$\xi=-1$

\title{
Media Literacy Skills and Social Media: A Portray of Teenagers in Urban Area
}

\author{
Ragil Tri Atmi*, Iswanda F. Satibi*, Indah R. Cahyani* \\ *Departmen of Information and Library, Universitas Airlangga \\ Kampus B, Jl. Dharmawangsa Dalam, Surabaya 60286, Indonesia
}

\begin{abstract}
What we know about association between social media and media literacy is largely based upon case studies that investigate how teenagers' behavior in digital environment. Although studies focusing on the level of media literacy skills towards social media have been conducted in recent years, much uncertainty still exists about the relationship between the media literacy skills and the use of social media among teenagers. This study aims to contribute to this growing area of research by exploring the level of media literacy skills and motivations among the teenagers towards social media in urban area. A quantitative descriptive survey research design was used to identify, analyze, and describe the media literacy skills of teenagers towards social media. The purposive sampling method was taken to appropriately select an evenly balanced group of participants. In total, 34 students participated, of which $83 \%$ living in the rural-urban fringe area, the intersection area between urban and farming field. It is evidently clear from the findings that the average level of media literacy skills among teenagers in urban area is at medium level. There is a high level of information dimension among teenagers, whereas other dimensions are fractionally less popular. On average, the level of dimensional motivations is medium. Teenagers seem to use social media to support their study and socially engage with friends. The result of this study confirm previous studies that focused on the level of media literacy among teenagers towards social media. Analysis of data shows that teenagers acknowledged the benefits of social media. However, no statistically significant difference between the mean sores of four sets of media literacy skills was evident. Media literacy is maturing, as evidenced by the significant understanding of social media in the digital environment.
\end{abstract}

Keywords: social media, media literacy skills, teenagers, urban area

\section{Introduction}

Within the advanced internet service and wider implementation of Web 2.0 over the globe, the role of social media towards media literacy also evolved into multi-dimensional approaches, frameworks, and models. Recently, media literacy concept has been encompassed by social media as one primary tool of teenagers to engage with society. This phenomena, however, has vary challenges since the societal environment in digital age offers different perspective of communication and many ways of interaction. Sonia Livingstone, Professor from London School of Economic, reported that, in average, teenagers have spent three hours a day in front of computer or gadget. Furthermore, it is reported that the most popular activities were playing games, watching online videos, and access social media [1].

To date, studies focusing on the level of media literacy skills towards social media have been conducted in many countries around the globe. However, much uncertainty still exists about the relationship between the media literacy skills and the use of social media among teenagers. Additionally, this study aims to contribute to this growing area of research by exploring the level of media literacy skills among the teenagers towards social media in urban area. In order to achieve the objectives, this study will be guided by the following sub-questions;

1. How social media been used by teenagers in urban area?
2. To what extend are teenagers aware of media literacy skills towards social media?
The emergent of social networking sites has been creating a new wave paradigm in society. The wide range development of social media and the internet have significantly affected many aspects of human life and its environment. Carlson and Lee [2] defined social media as, "online platforms that facilitate global collaboration and sharing among users. Consumers can easily obtain information from a vast, geographically dispersed group of people in social platform". The popular social media like Facebook, Twitter, Flickr, LinkedIn, and recently we have Google+, Instagram, Path, have been provided advantageous ways for people to communicate, build relationship and community virtually, information and knowledge sharing, documents transfers, and social movement [34]. Along with this growth, however, there is an increasing concern over web 2.0 and social media towards media literacy skills for teenagers.

What we know about association between social media and media literacy is largely based upon case studies that investigate how teenagers' behavior in digital environment. Buente and Robin [5] identified four dimensional motivations of social media usage among teenagers. First, informational utility. Teenagers using social media to find information through the internet. Furthermore, the convenience of searching information in social media allows teenagers to discover and share knowledge easily. Second, leisure or fun activities. Nowadays, social media offers interactive activities (e.g. online games) which provides teenagers with ability to collaborate and discuss their tasks synchronously. Third, commu- 
nication. The ability to engage teenagers with constant connectivity, which in turn makes their activities are no longer restricted by time and space. Fourth, one of distinguishing feature of social media is transaction. Although the features of social media are designed specifically for interaction and communication, the recent features of social media do provides a number of commercial benefits that are useful for teenagers who interested in ecommerce [6].

Thus far, several studies have attempted to evaluate the impact of social media on the teenagers behavior in Indonesia. In a study investigating the impact of social media towards interpersonal relationship among teenagers, Abadi et al [1] reported two major motivations associated with the use of social media: find information about their friends (78\%) and strengthening their friendship or connection in social media $(76 \%)$. Whilst previous studies have mainly been interested in questions concerning social media among teenagers' behavior, Potter [7] has taken a different approach by focusing on media literacy as a pinpoint. He sees the importance of media literacy skills among teenagers to overcome the impact of social media. As argued by Blake (cited in Potter [7]), the importance of teaching media literacy skills for teenagers because it would encompasses awareness of the source of the information and to better understand the communication technology. Most of the research on the association between social media and media literacy, however, is flawed methodologically. In addition, the lack of reliable instruments is particularly problematic for studies of social media towards media literacy. Despite the overwhelming development and benefits of social media for teenagers in urban area is technically still in its infancy.

The academic literature on media literacy has revealed the emergence of several extensive issues. Building on the work of Chen [8] and Lin [9] draw our attention to distinctive the framework of new media literacy. By drawing on the concept of new media literacy from functional-critical and consuming-presuming, Lin sets out nine indicators into the framework (Figure 1).

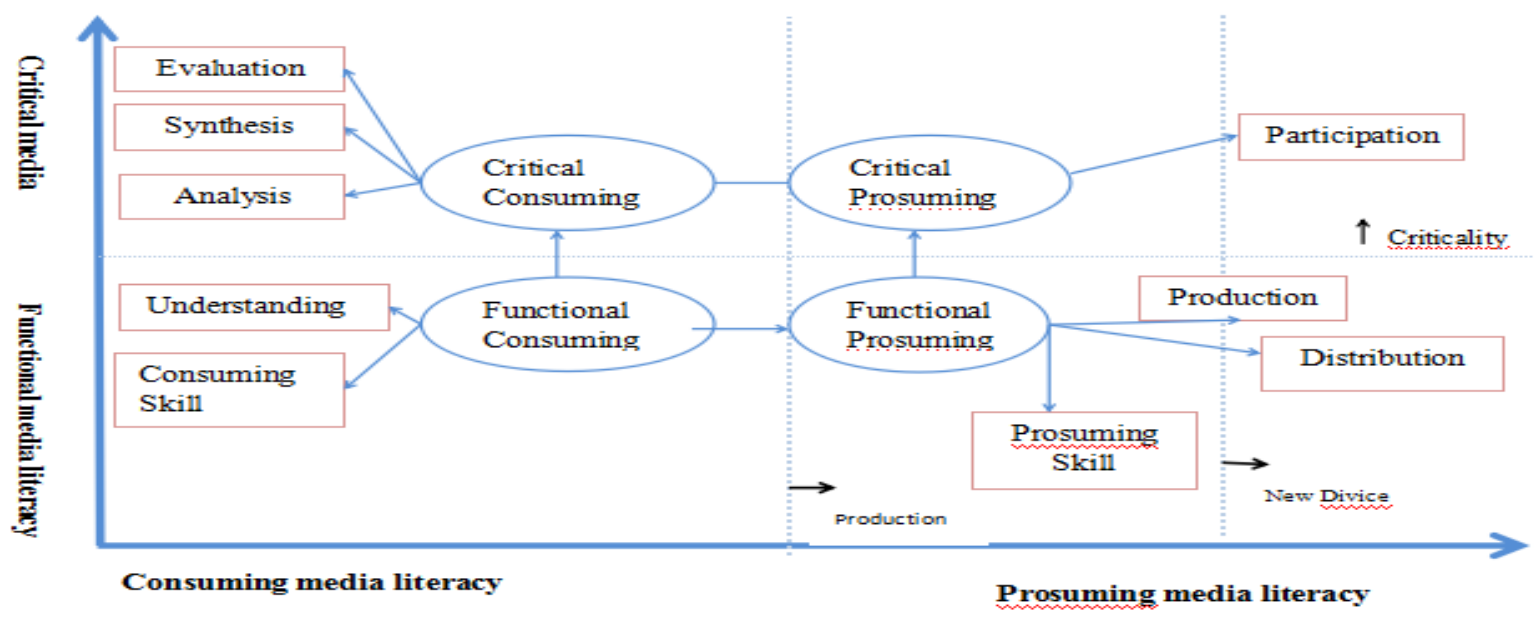

Figure 1. New Media Literacy Framework [9]

- Functional Consuming is an individual skill to access content of media and understand its meanings. This set of skills comprised two indicators; consuming skill and understanding.

- Critical Consuming refers to the ability of individual to interpret content of media towards social, economy, politics, and culture. This skill requires three indicators; analysis, synthesis, and evaluation.

- Functional Presuming is mostly related to the ability to participate in creating media content. It consists of three sub-skills; presuming skill, distribution, and production.

- Critical Presuming is a set of skills the requires a contextual interpretation of media. It is usually measured by individual's participation.

In view of all that has been mentioned so far, this review has demonstrated the shortcoming of media literacy skills among teenagers towards social media. Furthermore, there seems to be a small number of evidence to indicate the critical role of media literacy in urban area. Therefore, this study proposes the new media literacy framework provided by Lin et al. [9] as parametric indicators to captures the complexities of the phenomenon.

\section{Methods}

A quantitative descriptive survey research design was used to identify, analyze, and describe the media literacy skills of teenagers towards social media. This approach was taken to provide an accurate description and prediction of the population of interest as well as test the associational relationship. This method allow to work with a specific things to manipulate although it is heavily dependent on instrumentation for measurement and observation [10].

\section{Research Tools}

The population in this study consisted of teenagers from different junior high schools in Sidoarjo, Indonesia. The purposive sampling method was taken to appropriately select an evenly balanced group of participants. In total, 34 students participated, of which $83 \%$ living in the rural-urban fringe area, the intersection area between urban and farming field. The mean age of participants was 14 years.

\section{Research Conducting Method}

In the first phase of this study, the participants received an explanation of the project. Subsequently, participant were given a partially structured-questionnaire which constructed based on the nine indicators of new media literacy framework proposed by Lin [9]. The questionnaire was comprised of 49 scaled responses and 8 fixed responses. After all efforts, a total of 34 responses were received, of which 30 questionnaires completed, resulting in a response rate of $87 \%$.

\section{Findings}

While some results from this present research might have supported those previous studies, other results discovered startling findings from the respondents. By the end of the survey period, data had been collected from thirty students from five different junior high schools in Sidoarjo, East Java province, Indonesia, partici- 
pated in this research. The respondents fell between age ranges of 12-15; more than a half (53\%) were girls which accounted for $57 \%$ and $43 \%$ were boys. More than a half respondents $(53 \%)$ were 8 class students, while students from class 7 and class 9 accounted for $27 \%$ and $20 \%$, respectively. Table 1 illustrates the demographic information of respondents in this research.

Table 1. Demographic of Respondents

\begin{tabular}{|c|c|c|c|c|}
\hline Gender/Class & Class 7 & Class 8 & Class 9 & Total \\
\hline Boys & 6 & 6 & 1 & 13 \\
\hline Girls & 2 & 10 & 5 & 17 \\
\hline Grand Total & $\mathbf{8}$ & $\mathbf{1 6}$ & $\mathbf{6}$ & $\mathbf{3 0}$ \\
\hline
\end{tabular}

Respondents were asked to suggest kind of social media that actively been used in their daily activities. As can be seen from the Figure 2, 53\% respondents have more than three social medias whereas $47 \%$ only has engaged with one to three social media. Of these figures, Facebook and Blackberry Messengers were the most popular social media which share the same proportion $(43 \%)$. Instagram was substantially more common than WhatsApp (10\% and $3 \%$, respectively).

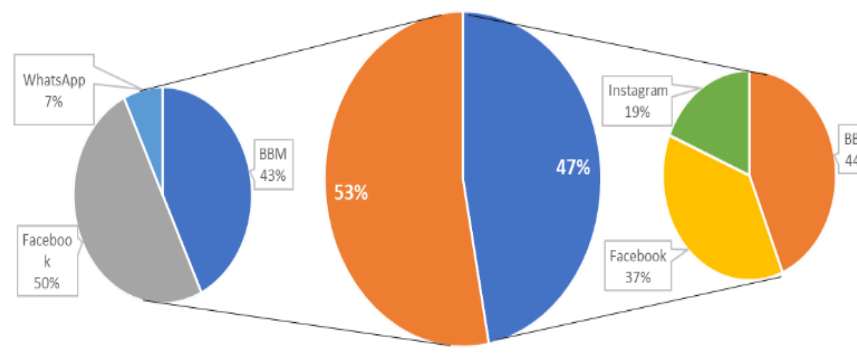

Figure 2. Social Media Choices and Uses among Teenagers

To better understand the glance of the use of social media by teenagers in urban area, respondents were asked to determine such activities on social media. The most striking result to emerge from the data is that the $30 \%$ of respondents used social media to find information to accomplish assignments. As can be seen from the Table 2, it is not surprising that almost half (44\%) of respondents were communicating through the social media, $23 \%$ expressed their personal existence and only $3 \%$ of respondents used social media to read online news.

In the second part of the survey, respondents were asked preferred devices or tools for accessing it. What stands out from this part was the dominance of smartphone as the prominent devices to access social media. When the respondents were asked the time that they spent on social media, almost two-thirds of respondents indicated that they spent about 30 to 60 minutes a day.

Table 2. The Preferred Activities on Social Media

\begin{tabular}{|l|l|l|}
\hline \multicolumn{1}{|c|}{ Activities } & Responses & $\%$ \\
\hline Find information & 9 & 30 \\
\hline Communication & 13 & 44 \\
\hline Updating personal activities & 7 & 23 \\
\hline Read online news & 1 & 3 \\
\hline Total & $\mathbf{3 0}$ & $\mathbf{1 0 0}$ \\
\hline
\end{tabular}

The benefits of using social media measured by a fixed responses question. A half of respondents expressed a desire for knowledge support while using social media. Whereas almost a quarter of respondents $(23 \%)$ welcomed the opportunity to focus on friendship, $17 \%$ agreed that social media supports their activities, and only $10 \%$ explicitly emphasized their personal existence.

\section{The Dimensions of Social Media}

In order to gather information about how teenagers' behavior in urban area use social media, 15 scaled questions were developed based on Buente and Robin's four dimensional motivations [5]. In total, there were 47 responses for this section. The results, as shown in Table 3 , indicate that there is a high level of information dimension among teenagers (3.7) whereas other dimensions are fractionally less popular. On average, the level of dimensional motivations is medium (3.1). Teenagers seem to use social media to support their study and socially engage with friends. This finding is consistent with that Madge who reported that collaborative learning tools provided by home institution was less popular for interaction in digital environment [10]. However, it is possible that these results may have been skewed by teenagers' perception of social media and internet.

Table 3. The Dimensions on Social Media among Teenagers in Urban Area

\begin{tabular}{|l|c|c|}
\hline Dimensions & Average & Level \\
\hline Information & 3.7 & High \\
\hline Leisure & 2.8 & Medium \\
\hline Communication & 3.1 & Medium \\
\hline Transaction & 2.9 & Medium \\
\hline Total Average & $\mathbf{3 , 1}$ & Medium \\
\hline
\end{tabular}

It is immediately apparent from the survey data that teenagers in urban area have a similar behavior in the digital environment. There is no significant differences in terms of activities preferred by boys and girls on social media. Not surprisingly, along with an increased access of internet and ICT advancement, teenagers experienced an easy access to information, communicate with their peer, updating personal information, and playing games [11-12]. Taken together, these results suggest that there is an association between ICT infrastructure and teenagers' behavior in urban area. These results, however, support previous studies focused on the impacts of using such technology on teenager's learning experience [13-14].

\section{Level of Media Literacy on Social Media}

Nine indicators were used to measure the different levels of media literacy among teenagers towards social media. Likert scale questions were constructed to measure the particular levels. In total, 28 statements were mapped into four levels of media literacy skills, which expressed through nine indicators.

Table 4. Level of Media Literacy Skills

\begin{tabular}{|l|l|l|}
\hline Media Literacy Skills & Average & Category \\
\hline Functional Consuming & 3.4 & High \\
\hline Critical consuming & 2.9 & Medium \\
\hline Functional presuming & 2.7 & Medium \\
\hline Critical presuming & 2.6 & Medium \\
\hline Total Average & $\mathbf{2 . 9}$ & Medium \\
\hline
\end{tabular}

As shown in Table 4, the average level of media literacy skills among teenagers in urban area is at medium level (2.9). The current study found that the only overwhelming skill is functional consuming (3.4), followed by critical consuming skill (2.9), functional presuming skill (2.7), and critical presuming skill (2.6).

Among nine indicators of media literacy skills, there are only three indicators scored significantly above 3 (high). Consistent with the literature, this study found that teenagers who reported using social media still having a lack of production and evaluation skills (Figure 3). The mean score (average) of these skills are accounted for 2.3 and 2.5 , respectively.

However, it is encouraging to compare this figure with that found by Abadi et al. [1] who found that the awareness to evaluate information in social media was considerably high. Thus, the evaluation skill is not the only key influencing the high level of functional consuming although there was no statistically significant 


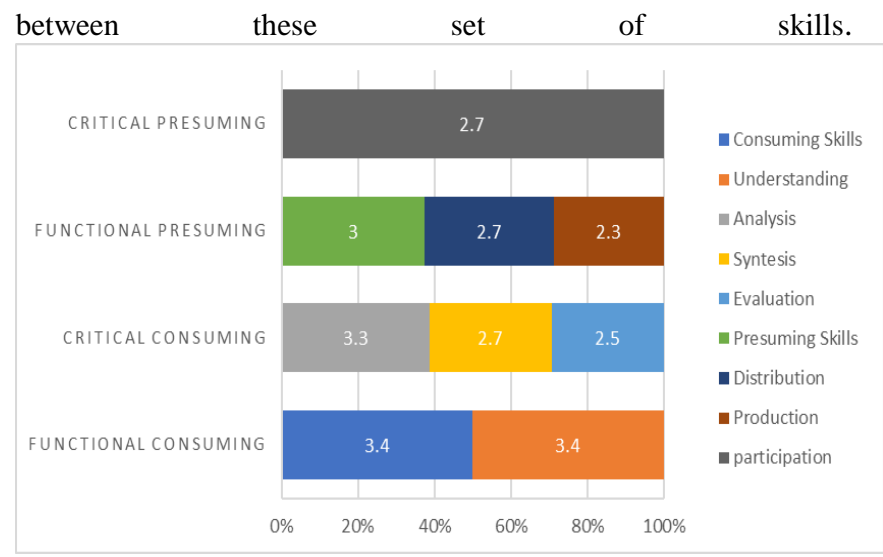

Figure 3. Levels of media literacy skills over nine indicators.

As Figure 4 shows, it can be seen that media literacy skills were subjected to girls, which dominated five skills. While the boys only heading in consuming skills (3.5). It is possible that these results do not represent the whole population of the study due to the lack of sampling method.

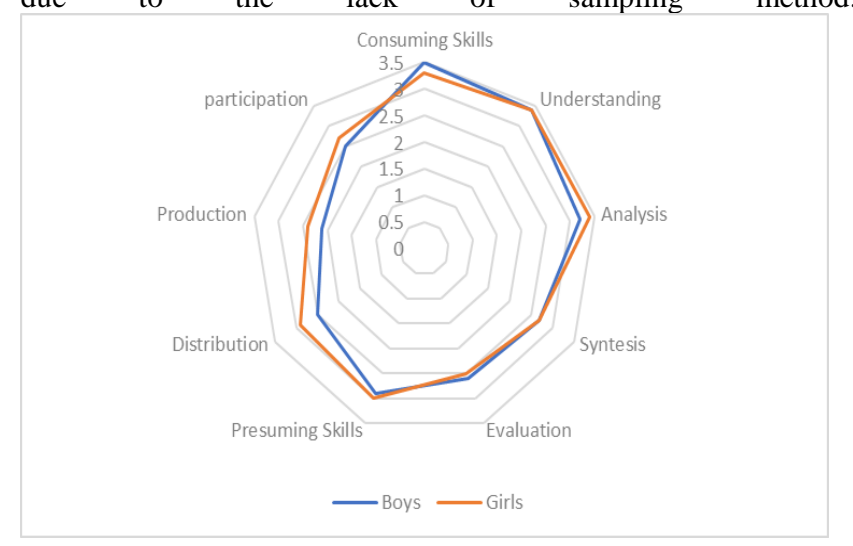

Figure 4. Gender differences in media literacy skills.

\section{Conclusion}

The result of this study confirm previous studies that focused on the level of media literacy among teenagers towards social media. Analysis of data shows that teenagers acknowledged the benefits of social media. However, no statistically significant difference between the mean sores of four sets of media literacy skills was evident. There is no need to completely change the way of teenagers' behavior and its environment. A minor adjustment on the school curricula may help to drive them immensely and collectively.

The considerable increase in the move towards media literacy among teenagers in Sidoarjo in social media with higher functional consuming skills, no doubt spurred by the overriding needs of information to obtain more insights, has been marked as potential literacy's skills. Slowly but steadily more and more social media infiltrated the way teenagers' behavior.

Media literacy is maturing, as evidenced by the significant understanding of social media in the digital environment. However, efforts are still needed to better understand the state of art of social media towards teenagers in the near future. Undoubtedly, the collaboration between educational institutions and parents is required to govern this radical shift. Finally, the present study was subject to a number of potential methodological weaknesses. Considerably more work will need to be done to determine the level of media literacy among teenagers.

\section{Reference}

[1] Abadi, T. W., Sukmawan, F.,Utari, D. A. Media Sosial dan Pengembangan Hubungan Interpersonal Remaja di Sidoarjo. KANAL: Jurnal Ilmu Komunikasi, 2016; 2(1), 95-106.

[2] Carlson, A., \& Lee, C. C. Followership and Social Media Marketing. Academy of Marketing Studies Journal, 19(1),2015; 80-101.

[3] Nasrullah, Rulli. Media Sosial: Perspektif Komunikasi, Budaya,dan Sosioteknologi. Bandung: PT. Remaja Rosdakarya;2015.

[4] Severin, W. J., \& Tankard, J. W. Teori Komunikasi: Sejarah, Metode, \& Terapan di Dalam Media Massa (5 ed.). Jakarta: Kencana;2005

[5] Buente, W., \& Robbin, A. Trends in Internet Information Behavior, 2000-2004. Journal of the Association for Information Science and Technology,2008; 59(11), 1743-1760.

[6] Rohmadi, Arif. Tips Produktif Ber-social Media: Manfaat aneka sosial media populer. Jakarta: Gramedia;2016.

[7] Potter, J. W. Media Literacy. New York: Sage Publications;2001.

[8] Chen, D. T., Wu, J., Wang, Y. M. Unpacking New Media Literacy; 2011.

[9] Lin, T. B., Jen-Yi, L., Deng, F., \& Lee, L. Understanding New Media Literacy: An Explorative Theoretical Framework. Journal of Educational Technology \& Society, 2013;16(4), 160.

[10] Wildemuth, B. M. Applications of Social Research Methods to Questions in Information and Library Science. Westport, Conn: Libraries Unlimited;2009.

[11] Koutsouris, A. The Emergence of the Intra-Rural Digital Divide: A Critical Review of the Adoption of ICTs in Rural Areas and the Farming Community. In 9th European IFSA Symposium (Vol. 4 No. 7);2010.

[12] Livingstone, S., Helsper, E. Balancing Opportunities and Risks in Teenagers' Use of the Internet: The Role of Online Skills and Internet Self-Efficacy. New media \& society,2010;12(2), 309-329.

[13] Gikas, J., Grant, M. M. Mobile Computing Devices in Higher Education: Student Perspectives on Learning with Cellphones, Smartphones \& Social Media. The Internet and Higher Education, 19,2013;18-26.

[14] Panekham, A. Exploring the role Social Media Plays in the Student Learning Experience of 2014 University Life in NZ; 2014. Retrieved from http://researcharchive.vuw.ac.nz/handle/10063/3720 